\title{
El movimiento social y la privatización
}

Ante el proceso privatizador del gobierno arenero existen dos hechos que llaman la atención. El primero es que las fuerzas sociales populares, exclusión hecha de los trabajadores del sector público, cuya privatización parece inminente, no han tomado conciencia de la gravedad ni de las consecuencias que para los sectores sociales populares traería tal medida y el segundo hecho es que algunos sectores sociales organizados parecen creer que es posible, al menos en su caso, detener el proceso privatizador.

Lo anterior exige algunas reflexiones. La primera, recordar cuál es la finalidad última del proceso privatizador. Es claro que no se trata de eficiencia o ineficiencia, de rentabilidad o no rentabilidad, de empleo o desempleo, de incremento o decremento en las tarifas, etc. Todo ello es discurso, retórica, justificaciones o tranquilizantes para los trabajadores y para la opinión pública. La finalidad del proceso privatizador es posibilitarle al capital "nacional" y trasnacional lucrar u obtener beneficios con las empresas e instituciones privatizadas. De allí que tengan los ojos puestos en instituciones como ANTEL, CEL, CEPA, INPEP, ISSS, FSV, etc. como prioridad; luego vendrían los mercados, los turicentros y los servicios públicos gratuitos como la salud y la educación.

La segunda reflexión recuerda que tenemos un gobierno de y para las fracciones de la clase capitalista que, a falta de un mejor calificativo, llamaríamos "modernizantes", las cuales conforman una nueva oligarquía con intereses en el comercio, en la industria, en las exportaciones y en la banca, con muchísimo poder y con una voracidad increíble, además de conexiones, no muy claras, con grupos económicos extranjeros. Hasta ahora han venido cediendo algunas migajas y parece que, ante una postura de no privatización rotunda y absoluta, se corre el riesgo de que no se les logre arrancar nada más que las migajas que han venido cediendo.

En consecuencia, la argumentación de la Asociación de Trabajadores de las Telecomunicaciones (ASTTEL), que considera que la privatización supondrá la cesantía de casi 4 mil empleados y el monopolio de las comunicaciones por parte de las transnacionales, las cuales dejarán sin telefonía rural, pública y social, es correcto. Compañías transnacionales como ITT, MCI y Sprint de Estados Unidos, NTT de Japón y Telecomunicaciones de España ya están operando con intermediarios en el país. La privatización de ANTEL se iniciaría con la creación del Consejo Salvadoreño de las Telecomunicaciones, una entidad estatal para regular las telecomunicaciones. Asimismo es correcto afirmar la existencia de una conspiración que consiste èn provocar deliberadamente atraso en los proyectos, para presentar a la institución como deficiente. Por su parte, los trabajadores afirman que son eficientes y proponen una modernización en los términos siguientes: luchar contra la corrupción, sustituir el equipo obsoleto y capacitar al personal. En 1994, las ganancias de ANTEL ascendieron a los 400 millones de colones. ASTTEL cuenta con el apoyo solidario de los trabajadores de otras instituciones que serán privatizadas, como 
ANDA y CEL (Diario Latino, 3 de enero de 1995, p. 3).

Ante estas realidades cabe preguntarse si ASTTEL y el movimiento social popular en general cuentan en la actualidad con la fuerza necesaria y suficiente para detener el proceso privatizador, ya que, en caso contrario, sería preferible buscar que el proceso privatizador beneficie al sector laboral de la institución, así como también a otros sectores sociales. Esto último no sólo es bueno en sí mismo, sino que, adicionalmente, podría posibilitar un apoyo solidario mayor para las propuestas de ASTTEL.

Por otra parte, nos parece que existe, al menos a nivel de declaración, un rechazo a la privatización por parte de distintos sectores sociales y, en consecuencia, sería procedente promover: (a) un foro de amplia participación popular para compartir la información disponible sobre las intenciones privatizadoras del gobiemo; (b) la integración de un comité técnico para estudiar los distintos casos de privatización, proponer alternativas razonables y viables, y asesorar a los trabajadores en cada caso particular; (c) la formulación de una estrategia unitaria, resultado de las deliberaciones del foro, para enfrentar la creciente ola privatizadora del gobierno.

Esta propuesta se fundamenta en el hecho de que la lucha contra la privatización puede constituirse en un aglutinador de los distintos sectores sociales $y$, en consecuencia, podría posibilitar enfrentarla de manera unificada. Ello presupondría crear un comité nacional representativo de los distintos sectores afectados con la privatización que obligara al gobierno a negociar el proceso privatizador.

Aparentemente, hasta ahora, sólo ASTTEL ha enfrentado en forma seria y responsable la intención privatizadora del gobierno. Sin embargo, las vendedoras del Mercado ex Cuartel, víctimas de lo que parece un siniestro planificado que recuerda las prácticas del pasado, están en contra de la privatización de dicho mercado. Los trabajadores de Instituto Salvadoreño de Turismo (ISTU), por su lado, han advertido que se encuentran organizados en todo el país y que tienen capacidad para paralizar las labores del instituto si el gobierno se niega a dialogar sobre la privatización. Los trabajadores organizados de ANDA denunciaron "el uso de personal privado por medio de contratistas, quienes están ejecutando de manera deficiente los trabajos encomendados, los cuales tienen que ser reparados por brigadas de la institución, generando una doble inversión, debido a que no poseen la experiencia necesaria, como la que han adquirido por más de veinte años los obreros de ANDA, lo que demuestra que la empresa privada no es la 'solución' para aumentar la eficiencia y productividad de la empresa, por el contrario sólo aumenta la explotación e incrementa el capital de una pequeña minoría, la que nos despoja de lo poco que tenemos".

La Central de Trabajadores Democráticos se pronunció en contra del costo de la vida, de la privatización y de la no consideración del aspecto social en las cumbres de presidentes centroamericanos. Por su parte, el CCTEM se pronunció en contra de las medidas económicas, porque la privatización dejará sin empleo a muchas personas

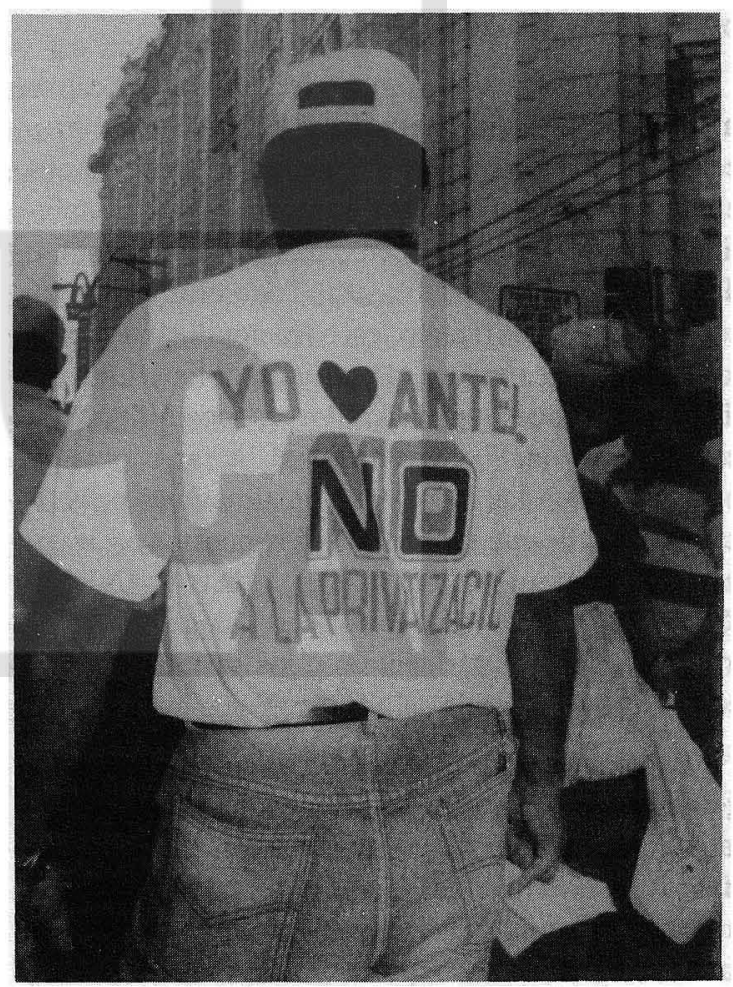


e incrementará la pobreza. No descartó realizar acciones de hecho, como marchas y concentraciones, hasta llegar a paros laborales; pero está dispuesto a dialogar con el gobierno para presentar su punto de vista y contribuir a que las medidas y la privatización dañen en lo más mínimo a los trabajadores. Igualmente, el ATMAG realizó una concentración en protesta por la privatización. Por su parte, el denominado Sector Laboral Democrático que aglutina a UPD, CGS, FESINCONSTRANS, FESTRAS, FEESITRABS, FESINTEXIC, FESINTRISEVA, ACATFAZ y ACOATLIT, ha pedido garantías de que no habrán despidos a causa de la privatización. Los trabajadores del INPEP también paralizaron sus labores ante la presunta privatización del instituto y los trabajadores del Ministerio de Obras Públicas efectuaron algunas marchas en protesta por la privatización.

Igualmente, 53 organizaciones integrantes de la Concertación Social y Popular se manifestaron contra las recientes medidas del gobierno, dentro de las cuales se incluye la privatización. Los trabajadores del Ministerio de Salud han efectuado marchas protestando por la privatización. El sector cooperativo también ha manifestado su desacuerdo con la privatización, al igual que distintas organizaciones no gubernamentales.

Como se puede apreciar de lo anterior, existe un rechazo a la privatización por parte del movimiento social organizado, así como algunos esfuerzos de carácter concertado, tal como lo evidencian los pronunciamientos firmados por organizaciones sociales. En consecuencia, en este momento lo adecuado es avanzar hacia la conformación de un sólo bloque para enfrentar de manera unificada y coherente los planes privatizadores del gobierno. Este bloque, además, debe tener capacidad propositiva y negociadora.

Después de las tristes experiencias de privatización del Instituto Regulador de Abastecimien- tos, del Instituto de Vivienda Urbana, de la banca y de otras muchas empresas e instituciones públicas, en las cuales la batalla se dio de manera aislada, es importante conformar un sólo bloque social popular en contra de los intereses mezquinos del capital y del gobierno arenero. Adicionalmente, este bloque social popular podría contar con el respaldo de los partidos de la oposición real presentes en la asamblea legislativa.

La coyuntura es histórica. La medida más importante de todas las propuestas por el gobierno es la privatización. No percatarse de ello y permitir ser distraído por otras acciones menos relevantes, sólo puede reflejar miopía política e ignorancia en materia económica y social. De allí que tanto el movimiento social popular como los partidos políticos de oposición, en particular el FMLN, tienen la obligación de enfilar sus baterías políticas hacia la pretensiones privatizadoras del gobierno.

Recordemos de nuevo que el gobierno arenero, al igual que cualquier otro gobierno, no es propietario de la cosa pública. En consecuencia, la privatización, así como la forma en que se lleve a cabo, cuando ésta proceda si éste es el caso, debe de ser resultado de una consulta popular seria. Actuar de otra manera sólo evidenciaría una actitud totalitaria y la no comprensión de las implicaciones de vivir en democracia. Desafortunadamente, el hecho, en sí mismo, es serio y sus repercusiones económicas y sociales son graves, tal como lo evidencia el caso de la privatización de la banca, acerca de la cual ahora se escuchan no sólo lamentos, sino también propuestas de reprivatización. Pero ello sólo evidencia la falta de seriedad y objetividad con la cual se tratan, algunas veces, asuntos de mucha trascendencia. Nada se puede hacer cuando la leche ya está derramada. 